Tropical Journal of Pharmaceutical Research November 2014; 13 (11): 1845-1851

ISSN: $1596-5996$ (print); 1596-9827 (electronic)

(C) Pharmacotherapy Group, Faculty of Pharmacy, University of Benin, Benin City, 300001 Nigeria.

All rights reserved.

Available online at http://www.tjpr.org

Original Research Article

http://dx.doi.org/10.4314/tjpr.v13i11.11

\title{
Effect Effects of Auricularia auricula Polysaccharides on Exhaustive Swimming Exercise-Induced Oxidative Stress in Mice
}

\author{
Haitao Hao \\ Department of Physical Education and Military Training, China Jiliang University, Hangzhou 310018, PR China
}

*For correspondence: Email: yanzjfeiwei@163.com; Tel: +86 13588345075; Fax: +86 057186872362

Received: 11 June 2014

Revised accepted: 16 October 2014

\begin{abstract}
Purpose: To determine the effects of polysaccharides from Auricularia auricula (AAPS) on exerciseinduced oxidative stress in mice.

Methods: The animals were divided into four groups: control (C), low, middle, and high-dose AAPstreated ( $L A, M A$, and $H A$, respectively). C group received physiological saline solution while $A A P S-$ treated groups received different doses of AAPs (50,100, and $200 \mathrm{mg} / \mathrm{kg}$ ) via oral gavage once a day for 28 days, followed by an exhaustive swimming exercise. Swimming times were recorded for each animal after which malondialdehyde (MDA), 8-hydroxydeoxyguanosine (8-OHdG), superoxide dismutase (SOD), glutathione peroxidase (GPX), and catalase (CAT) were determined.

Results: Exhaustive swimming times were significantly prolonged in all AAPs-treated animals as compared with controls. In all treatment groups, serum and muscle MDA levels were significantly lower than those in the $C$ group, whereas in the MA- and HA-treated groups, a decrease was also seen for liver MDA levels. Furthermore, the concentration of 8-OHdG was significantly reduced in serum, liver, and muscle in all AAPs-treated animals. In contrast, all AAPs treatment groups exhibited significantly higher SOD activity in serum, liver, and muscle. Serum and liver GPX activity was also significantly increased in all animals receiving AAPs treatment, with MA- and HA-treated mice exhibiting an additional augmented GPx activity in muscle. Serum and liver catalase activities in the MA and HAtreated groups, and catalase activity in muscle in all AAPs treatment cohorts, were significantly higher. Conclusion: Polysaccharides from Auricularia auricula enhance exercise endurance and possess protective effects against exhaustive swimming exercise-induced oxidative stress in mice.
\end{abstract}

Keywords: Exhaustive swimming, Malondialdehyde, 8-Hydroxydeoxyguanosine, Superoxide dismutase, Glutathione peroxidase, Catalase

Tropical Journal of Pharmaceutical Research is indexed by Science Citation Index (SciSearch), Scopus, International Pharmaceutical Abstract, Chemical Abstracts, Embase, Index Copernicus, EBSCO, African Index Medicus, JournalSeek, Journal Citation Reports/Science Edition, Directory of Open Access Journals (DOAJ), African Journal Online, Bioline International, Open-J-Gate and Pharmacy Abstracts

\section{INTRODUCTION}

Edible mushrooms have been recognized as important food items since ancient times and their consumption is increasing because of their significant role in human health, nutrition, and disease [1]. Auricularia auricula, also known as "black tree ear," a precious macrofungus, is the fourth most important cultivated mushroom used by humans throughout the world [2] and has a history as traditional medicinal application in China. Polysaccharides have been identified as one of the main bioactive components of Auricularia auricula. The main monosaccharide That make up the polysaccharides from Auricularia auricula (AAPs) are glucose $(72 \%)$, mannose $(8 \%)$, xylose $(10 \%)$, and fucose (10 $\%)$. The polysaccharide backbone chain is $(1 \rightarrow 3)$ 
$\beta$-D-glucans [3]. Recent scientific evidence suggest that AAPs have multiple biological activities, including antioxidant, antiviral, antiinflammatory, anti-tumor, hypoglycemic, hypolipidemic, anticoagulant, and anticomplement activities as well as cardioprotective effects [4]. The aim of the present study was to determine the effects of AAPs on exercise-induced oxidative stress by measuring MDA and 8-hydroxydeoxyguanosine (8-OHdG) levels and the activities of the main antioxidant enzyme in the blood, liver, and muscle of mice.

\section{EXPERIMENTAL}

\section{Chemicals}

Commercial assay kits for the detection of MDA were purchased from Beijing SINO-UK Institute of Biological Technology (Beijing, China), and kits for the detection of SOD, GPx, and CAT were purchased from Nanjing Jiancheng Bioengineering Institute (Nanjing, China). Assay kits for 8-OHdG were purchased from the Control of Aging, Nikken SEIL Co., Ltd. (Shizuoka, Japan). All other chemicals used were of analytical grade and purchased from local suppliers.

\section{Animals}

The mice were allowed to acclimatize to the laboratory environment for one week prior to the experiments. After this period, they were randomly divided in four experimental groups (eight mice per group). All mice were provided a normal diet and water ad libitum. The groups and the treatment are as follows:

(i) C group: physiological saline;

(ii) LA group: AAPs, $50 \mathrm{mg} / \mathrm{kg}$ body weight (bw);

(iii) MA group: AAPs, $100 \mathrm{mg} / \mathrm{kg}$ bw;

(iv) HA group: AAPs, $200 \mathrm{mg} / \mathrm{kg}$ bw.

Each APPs dose was dissolved in $2.0 \mathrm{~mL}$ of physiological saline; the control group received the same volume of physiological saline only. Physiological saline or AAPs was administered once a day for 28 consecutive days via oral gavage using a feeding needle. The rationale for the selection of the doses was based on findings in our previous experiments and some early literature [6]. The doses of AAPs (50 - $200 \mathrm{mg} / \mathrm{kg}$ bw) were confirmed to be suitable and effective in the tested mice.

\section{Auricularia auricula and chemicals}

The dried fruit body of Auricularia auricula was purchased from a local market (Hangzhou,
China) in September 2012 and stored in a glass dryer at room temperature until used. The plant samples were identified by Professor M.J. Wang of the College of Life Sciences, China Jiliang University, Hangzhou, China. A voucher specimen (no. CJL 12841) was deposited in the herbarium of China Jiliang University.

\section{Preparation of crude polysaccharides from Auricularia auricula}

Crude AAPs were prepared as previously described [5], with slight modification. Fruit bodies of Auricularia auricula were initially dried at $70{ }^{\circ} \mathrm{C}$ and ground in a mortar. Dried powder $(100 \mathrm{~g})$ was pre-extracted with $95 \%$ ethanol using a Soxhlet apparatus (model SXT-06, HongJi Instrument Co, Ltd, Shanghai, China) in order to remove pigments and some soluble materials, including free sugars, amino acids and some phenols. The pretreated powder was extracted three times with five volumes of distilled water under constant stirring for $5 \mathrm{~h}$ in a $90^{\circ} \mathrm{C}$-water bath. The mixture was centrifuged at $2000 \mathrm{~g}$ for $20 \mathrm{~min}$ and the supernatant was filtered through a gauze and Whatman glass fiber filter. The supernatant was concentrated under vacuum at $40{ }^{\circ} \mathrm{C}$ and dialyzed with a dialysis membrane cut-off of $3500 \mathrm{Da}$. The extract was precipitated by the addition of $95 \%$ ethanol to a final concentration of $80 \%$. Subsequently, the precipitate was recovered by centrifugation, washed with acetone, re-dissolved in a small amount of distilled water, and lyophilized to obtain the final usable form of AAPs.

\section{Animals and breeding conditions}

Male mice of the original Kunming strain (18-22 g) were obtained from the Zhejiang Province Center for Disease Control and Prevention (Hangzhou, China) and housed under standardized conditions $\left(25 \pm 2^{\circ} \mathrm{C}\right.$, normal $12 / 12$ h light/dark cycle, humidity $50 \pm 10 \%$ ) with access to pelleted diet and tap water ad libitum. All animal experiments were in accordance with the National Research Council Guidelines of China for the Care and Use of Laboratory Animals (No. 2 of the State Science and Technology Commission on November 14, 1988, China), and were approved (no. 2013018) by the Comments of the Animal Ethics Committee of China Jiliang University, Hangzhou, China.

\section{Exhaustive swimming test}

All mice were trained to perform a swimming exercise for 10 min without any weight burden every other day. The swimming exercise was 
carried out in an acrylic plastic tank (90 × $60 \times 60$ $\mathrm{cm}$ ) filled with water to a depth of $35 \mathrm{~cm}$ and kept at $25 \pm 1^{\circ} \mathrm{C}$. After 28 days, the mice were subjected to the exhaustive swimming test one hour after the last oral administration. The tail of each mouse was loaded with a tin wire, which was $7 \%$ of its body weight. The swimming period was considered the time spent floating, struggling, and moving necessarily until exhaustion and possible drowning. Exhaustion was determined by observing loss of coordinated movements and failure to return to the surface within $10 \mathrm{sec}$ [7].

\section{Analysis of biochemical parameters}

Following the exhaustive swimming test, blood samples were collected in Eppendorf tubes by quick removal of the eyeball from the socket under general anesthesia with a pair of tissue forceps. The blood was allowed to coagulate for $30 \mathrm{~min}$ at room temperature, and serum was prepared by centrifugation at $2,000 \times \mathrm{g}$ for 10 min. After blood collection, the mice were immediately sacrificed by cervical dislocation, and the liver and hind limb skeletal muscles quickly harvested and immediately stored at -20 ${ }^{\circ} \mathrm{C}$ until analysis. MDA, SOD, and CAT were determined using the thiobarbituric acid (TBA), xanthine/xanthine oxidase, and ammonium molybdate colorimetric method, respectively [810]. Levels of 8-OHdG were measured using ELISA and those of GPx using a modification of the method of Rotruck et al [11,12]. Measurements were performed according to the recommended procedures provided by the commercial diagnostic kits.

\section{Statistical analysis}

The results are expressed as mean \pm S.D. and were analyzed by one-way ANOVA followed by Least-Significant Difference Test (LSD) using SPSS software (version 15.0). $P<0.05$ was considered significant.

\section{RESULTS}

\section{Effects of AAPs on exhaustive swimming time}

As shown in Fig. 1, the exhaustive swimming times in the LA, MA, and HA groups (517.3 \pm $75.3,608.9 \pm 62.7$, and $783.8 \pm 84.9 \mathrm{sec}$, respectively) were significantly higher than that in the $\mathrm{C}$ group (379.6 $\pm 48.9 \mathrm{~s})(p<0.05)$. These results suggest that AAPs have anti-fatigue activity and could enhance exercise endurance.
Effect of AAPs on serum, muscle, and liver MDA levels

Similar to the effect on performance in the exhaustive swimming test, AAPs also exerted a significant effect on MDA levels as demonstrated in Fig. 2. Serum MDA levels of mice in the LA, $\mathrm{MA}$, and HA groups $(4.96 \pm 0.71,4.37 \pm 0.53$, and $4.21 \pm 0.62 \mathrm{nmol} / \mathrm{L}$, respectively) showed a significant reduction in comparison with those of control mice $(5.47 \pm 0.68 \mathrm{nmol} / \mathrm{L})(p<0.05)$. Comparable results were found for muscle MDA levels in the C, LA, MA, and HA groups (3.58 \pm $0.62,3.16 \pm 0.43,2.93 \pm 0.37$, and $2.54 \pm 0.39$ $\mathrm{nmol} / \mathrm{mg}$ protein, respectively) $(p<0.05, \mathrm{C}$ versus AAPs-treated mice). Similarly liver MDA levels in the MA and HA groups (5.48 \pm 0.71 and $5.11 \pm 0.48 \mathrm{nmol} / \mathrm{mg}$ protein, respectively),

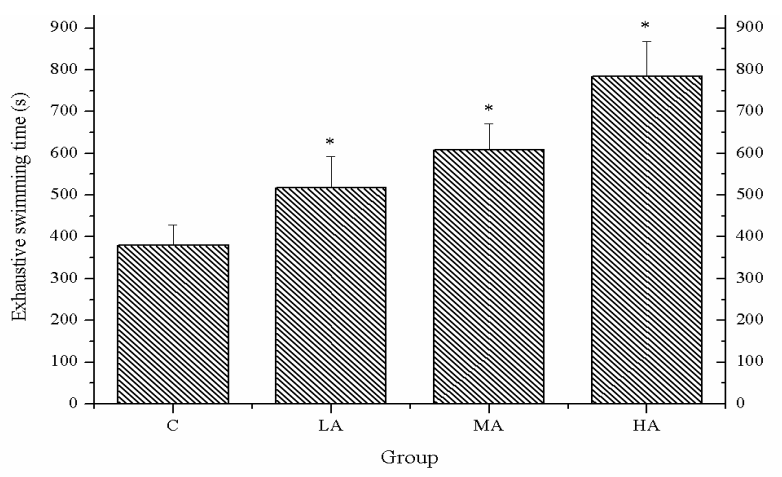

Fig 1: Effects of AAPs on exhaustive swimming time of mice. Values are expressed as mean \pm S.D. of mice per group; ${ }^{*} p<0.05$, when compared with those in the C group

were also significantly lower than those observed in the $\mathrm{C}$ group $(6.41 \pm 0.76 \mathrm{nmol} / \mathrm{mg}$ protein) $(p<$ $0.05)$. Although liver MDA levels in the LA group $(6.23 \pm 0.69 \mathrm{nmol} / \mathrm{mg}$ protein) were reduced, no significant difference was found between the control and LA-treated mice.

\section{Effect of AAPs on serum, muscle, and liver 8- OHdG levels}

AAPs treatment significantly reduced levels of 8OHdG (Fig. 3). Serum, liver, and muscle 8-OHdG levels were affected in all three APPs-treated groups with serum levels in LA, MA, and HAtreated mice of $1.42 \pm 0.21,1.09 \pm 0.16$, and $0.83 \pm 0.11 \mathrm{ng} / \mathrm{mL}$, respectively, compared with $1.61 \pm 0.24 \mathrm{ng} / \mathrm{mL}$ in the $\mathrm{C}$ group $(p<0.05)$. Levels in the liver were found to be $4.56 \pm 0.56$, $3.26 \pm 0.43,2.84 \pm 0.36$, and $2.01 \pm 0.39 \mathrm{ng} / \mu \mathrm{g}$ DNA for the C, LA, MA, and HA cohorts ( $p<$ 0.05 , C versus AAPs-treated animals). Compared with those of the $\mathrm{C}$ group $(2.84 \pm 0.41$ $\mathrm{ng} / \mu \mathrm{g}$ DNA), muscle $8-\mathrm{OHdG}$ levels in the LA, 
$\mathrm{MA}$, and HA groups $(2.07 \pm 0.37,1.42 \pm 0.26$, and $1.26 \pm 0.21 \mathrm{ng} / \mathrm{\mu g}$ DNA, respectively) were also significantly lower $(p<0.05)$.

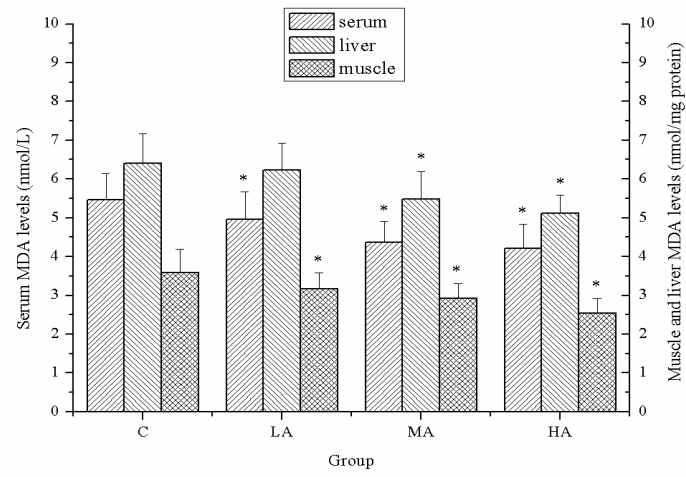

Fig 2: Effect of AAPs on serum, muscle, and liver MDA levels of mice subjected to the exhaustive swimming test. Values are expressed as mean \pm S.D. of mice per group; ${ }^{*} p<0.05$ compared with those in the $\mathrm{C}$ group

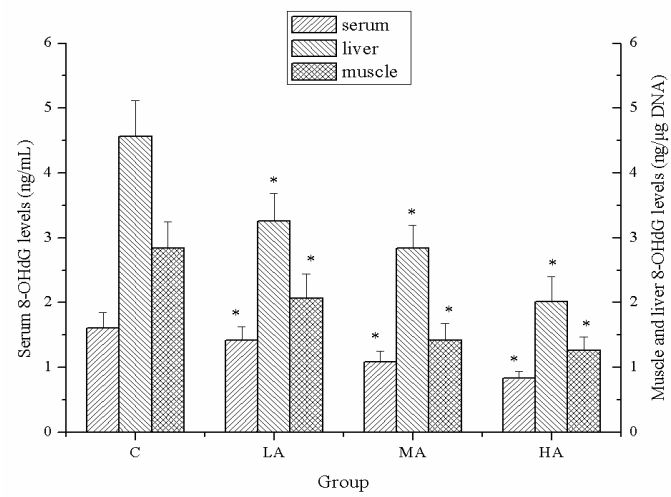

Fig 3: Effects of AAPs on serum, muscle, and liver 8OHdG levels of mice. Values are expressed as mean \pm S.D. of mice per group; ${ }^{*} p<0.05$, when compared with those in the $\mathrm{C}$ group

\section{Effect of AAPs on serum, muscle, and liver SOD activity}

Figure 4 demonstrates the effects of AAPs on serum, muscle, and liver SOD activity of mice. Compared with the $C$ group $(158.71 \pm 14.36$ $\mathrm{U} / \mathrm{L})$, serum SOD activity in the LA, MA, and HA groups $(187.89 \pm 18.74,203.84 \pm 19.69$, and $237.69 \pm 22.37 \mathrm{U} / \mathrm{L}$, respectively) was significantly higher $(p<0.05)$. This pattern was also seen for SOD activity in the liver with values of $102.34 \pm 12.39,116.81 \pm 14.87$, and $126.98 \pm$ $12.68 \mathrm{U} / \mathrm{mg}$ protein in the LA, MA, and HA groups, respectively. These values were significantly higher than the ones in the control mice $(88.63 \pm 10.62 \mathrm{U} / \mathrm{mg}$ protein) $(p<0.05)$ as were those measured in muscle: $149.76 \pm 18.77$, $178.43 \pm 15.39$, and $196.51 \pm 22.34 \mathrm{U} / \mathrm{mg}$ protein for LA, MA, and HA-treated mice, respectively.
Similar to the activity in the liver, this increase was significant in all groups in comparison with the activity in the $C$ group $(119.26 \pm 16.84 \mathrm{U} / \mathrm{mg}$ protein) $(p<0.05)$.

\section{Effect of AAPs on serum, muscle, and liver GPX activity}

As can be seen from Fig, 5, AAPs also affected GPx activity with activity measures in serum of the LA, MA, and HA groups significantly higher than those of control mice (122.69 \pm 14.51 , $128.73 \pm 12.78,146.52 \pm 15.66$, and $92.23 \pm$ $10.36 \mathrm{U} / \mathrm{L}$, respectively) $(p<0.05)$. Similarly, GPx activity in the liver was also highly induced in the LA, MA, and HA groups compared with its value in the control group $(78.94 \pm 5.41,96.87 \pm$ $8.97,108.73 \pm 10.26$, and $58.69 \pm 6.23 \mathrm{U} / \mathrm{mg}$ protein, respectively) $(p<0.05)$. The GPx activity in muscle, on the other hand, was only significantly elevated in MA $(10.25 \pm 1.28 \mathrm{U} / \mathrm{mg}$ protein) and HA-treated mice $(11.63 \pm 1.37 \mathrm{U} / \mathrm{mg}$ protein) in comparison with what was observed in control mice $(8.36 \pm 1.03 \mathrm{U} / \mathrm{mg}$ protein) $(p<$ $0.05)$. Although the GPx activity in muscle in the LA group (8.89 $\pm 1.14 \mathrm{U} / \mathrm{mg}$ protein) were also higher than that in the $C$ group, this difference was not significant $(p>0.05)$.

\section{Effect of AAPs on serum, muscle, and liver CAT activity}

Figure 6 shows the effects of AAPs on serum, muscle, and liver CAT activity of mice. Compared with the $C$ group $(49.32 \pm 5.69 \mathrm{U} / \mathrm{L})$, the CAT activity in serum in the MA and HA groups (58.73 \pm 5.06 and $64.55 \pm 7.21 \mathrm{U} / \mathrm{L}$, respectively) was significantly higher $(p<0.05)$. Although the serum CAT activity in LA-treated mice (50.49 \pm $6.54 \mathrm{U} / \mathrm{L}$ ) was also higher than that of mice in the C group, this difference was not significant $(p>$ $0.05)$. Similarly, compared with the $C$ group (16.38 $\pm 2.13 \mathrm{U} / \mathrm{mg}$ protein), the CAT activity in liver in the MA and HA groups $(19.83 \pm 2.22$ and $24.55 \pm 2.06 \mathrm{U} / \mathrm{mg}$ protein, respectively) was significantly higher $(p<0.05)$. Furthermore, although the liver CAT activity in the LA group $(17.46 \pm 1.98 \mathrm{U} / \mathrm{mg}$ protein) was also higher than that in the $C$ group, no significant difference was observed $(p>0.05)$. The CAT activity was also increased compared with that in the $C$ group (7.84 $\pm 1.03 \mathrm{U} / \mathrm{mg}$. prot) in muscle in the LA, MA, and $\mathrm{HA}$ groups $(9.36 \pm 0.94,11.84 \pm 1.21$, and $12.62 \pm 1.36 \mathrm{U} / \mathrm{mg}$ protein, respectively) $(p<$ $0.05)$. 


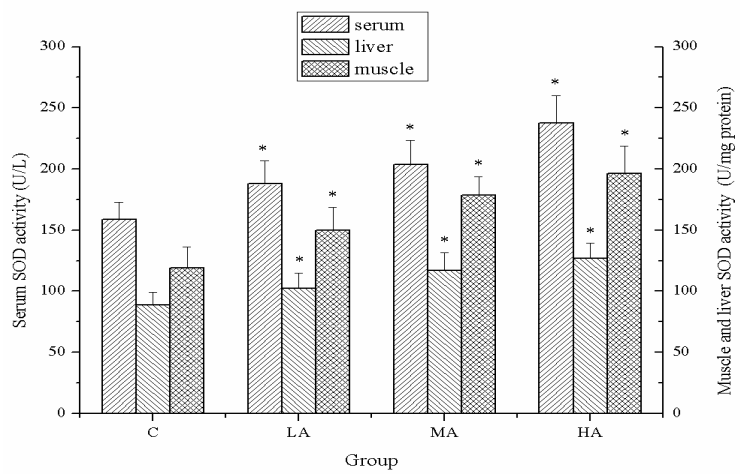

Fig 4: Effect of AAPs on serum, muscle, and liver SOD activity of mice. Values are expressed as mean \pm S.D. of mice per group; ${ }^{*} p<0.05$, when compared with those in the $\mathrm{C}$ group

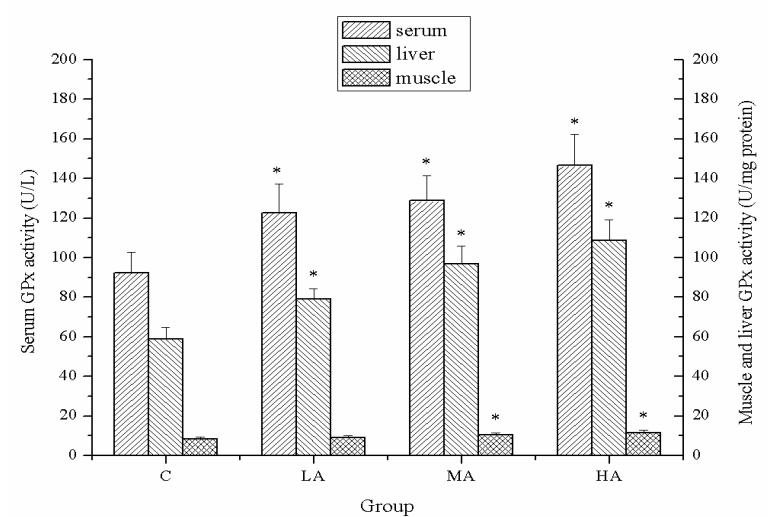

Fig 5: Effect of AAPs on serum, muscle, and liver GPx activity of mice. Values are expressed as mean \pm S.D. of mice per group; ${ }^{*} p<0.05$ compared with those in the $\mathrm{C}$ group

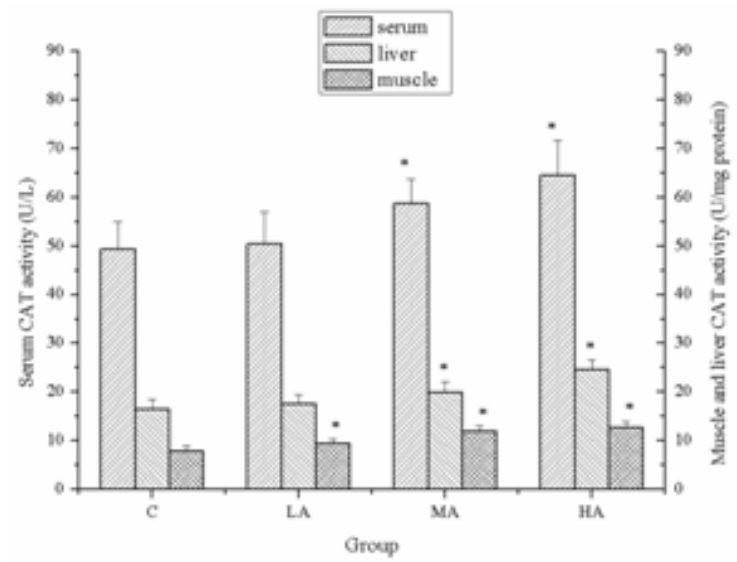

Fig 6: Effect of AAPs on serum, muscle, and liver CAT activity of mice. Values are expressed as mean \pm S.D. of mice per group; ${ }^{*} p<0.05$ compared with those in the $\mathrm{C}$ group

\section{DISCUSSION}

It is well documented that regular physical exercise has several beneficial effects, thereby acting as an effective means of preventing chronic diseases [13]. However, exhaustive exercise can produce a large quantity of reactive oxygen species (ROS) due to a dramatic increase in oxygen uptake at both the whole body and local tissue level [11]. Exercise can produce an imbalance between ROS and antioxidants, which is referred to as oxidative stress [14]. In the past three decades, several studies have indicated that oxidative stress can result in extensive lipid, protein, and DNA damage, which may lead to cell dysfunction, aging, carcinogenesis, and neurodegenerative and cardiovascular diseases [15]. Accumulated evidence has shown that increased antioxidant enzyme activity, increased resistance to oxidative stress, and lower levels of oxidative damage may protect against oxidative stressrelated damage to tissues and, on a microscopic level, to cellular macromolecules $[15,16]$. Recently, attention has increased to the consumption of functional food ingredients such as flavonoids, polysaccharides, saponins, and phenolic compounds, which might play a role in preventing oxidative stress. In this study, the effects of AAPs on exhaustive swimming exercise-induced oxidative stress were evaluated by measuring corresponding biochemical parameters in AAPS and control-treated mice.

Swimming was chosen as a suitable model since it is a natural behavior of rodents. The exhaustive swimming exercise method is known to cause less mechanical stress and injury and results in improved redistribution of blood flow between tissues without significant variations in cardiac output and heart rate, the latter of which may minimize the magnitude of ROS-induced injury [17]. In the present study, AAPs significantly prolonged exhaustive swimming time of mice, which suggests that AAPs have anti-fatigue activity and could enhance exercise endurance. The delicate physiological balance between oxidative reactions and antioxidant capacity may be perturbed by intense physical activity [11]. Reactive oxygen species cause lipid peroxidation of polyunsaturated fatty acids in biological membranes and blood [18]. Evidence prevails that lipid peroxidation is involved in damage to specific mitochondrial proteins and transport systems by direct inhibition of enzymes, resulting in loss of mitochondrial integrity. Lipid peroxidation is thought to be a prominent and especially deleterious form of neuronal oxidative injury by damaging the neuronal membrane [19]. Malondialdehyde, one of the final products of polyunsaturated fatty acid peroxidation, is commonly known as a marker of oxidative stress and antioxidant status during exercise. In the present study, AAPs significantly decreased MDA levels in the blood, liver, and muscle of 
mice, suggesting that AAPs could prevent exhaustive exercise-induced lipid oxidation.

Several studies have shown that oxidative stress induced by exhaustive exercise can result in extensive DNA damage. Increased DNA damage can induce the synthesis of a variety of misfolded proteins and therefore impair cellular function $[11,15]$. 8-hydroxydeoxyguanosine is produced by an enzymatic cleavage following 8hydroxylation of the guanine base of DNA. In several studies, 8-OHdG has been evaluated as a biomarker of oxidative DNA damage since it represents $5 \%$ of the total oxidized bases in the DNA and is present in quantities that can be readily detected [20]. In the present study, AAPs significantly decreased 8-OHdG levels in blood, liver, and muscle of mice, which suggest that AAPs could prevent exhaustive exercise-induced DNA damage. The mechanism by which exercise reduced the accumulation of $8-\mathrm{OHdG}$ is unclear, although the upregulation of the activity of DNA repair enzymes could be an important means by which exercise decreases nuclear DNA damage. However, further studies are needed to investigate this potential mechanism.

Previous studies have demonstrated that ROS generation during strenuous exercise evokes changes in the activity of the antioxidant defense systems, based on both enzymatic and nonenzymatic antioxidants. Antioxidant enzymes provide the first line of cellular defense against ROS that cause oxidative stress [6]. Primary antioxidant enzymes include SOD, GPx, and CAT. Each of these antioxidant enzymes performs a reduction of a particular ROS. Several studies have reported a significant decrease in SOD, GPx, and CAT activity after exhaustive exercise $[11,16,19]$. The decrease in the activity of these enzymes may predispose tissues to free radical damage. To our knowledge, our data are the first to show that AAPs significantly increased SOD, GPX, and CAT activity in the blood, liver, and muscle of mice. We therefore suggest that AAPs are able to upregulate main antioxidant enzyme activity to protect against oxidative stress-induced injury during exhaustive exercise.

\section{CONCLUSION}

This study shows that AAPs can enhance exercise endurance and possesses a protective effect against exhaustive swimming exerciseinduced oxidative stress in mice. The mechanism underlying these effects is based on a decrease in MDA and 8-OHdG levels and an increase in the main antioxidant enzyme activity in the serum, liver and muscle of mice.

\section{ACKNOWLEDGEMENT}

This work was supported by funds from Association of Higher Education of Zhejiang Province, PR China (no. ZGT201124).

\section{REFERENCES}

1. Hassan FRH, Ghada MM. Studies on submerged culture conditions for mycelial biomass production of wood ears mushroom (Auricularia polytricha). Middle East J Agric Res 2012; 1: 33-39.

2. Zhang $H$, Wang $Z Y$, Yang $L$, Yang $X$, Wang $X$, Zhang $Z$. In vitro antioxidant activities of sulfated derivatives of polysaccharides extracted from Auricularia auricular. Int J Mol Sci 2011; 12: 3288-3302.

3. Ukai S, Kiho $T$, Hara C, Kuruma I, Tanaka Y. Polysaccharides in fungi. XIV. Anti-inflammatory effect of the polysaccharides from the fruit bodies of several fungi. J Pharmacobiodyn 1983; 6: 983-990.

4. Takeujchi H, He P, Mooi LY. Reductive effect of hotwater extracts from woody ear (Auricularia auriculajudae Quel.) on food intake and blood glucose concentration in genetically diabetic KK-Ay mice. J Nutr Sci Vitaminol (Tokyo) 2004; 50: 300-304.

5. Wu Q, Tan Z, Liu H, Gao L, Wu S, Luo J, Zhang W, Zhao $T, \quad Y u J, \quad X u X$. Chemical characterization of Auricularia auricula polysaccharides and its pharmacological effect on heart antioxidant enzyme activities and left ventricular function in aged mice. Int J Biol Macromol 2010; 46: 284-288.

6. Zhu L, Wang ZY. Effects of polysaccharides from Auricularia auricula on Fatigue in mice. Acta Nutri Sinica 2008; 30: 450-433.

7. Li SS, Chen ZC, Zhang CH. Effect of tao-hong-si-wutang, a traditional Chinese herbal medicine formula, on physical fatigue in mice. Afr J Tradit Complement Altern Med 2012; 10: 60-65.

8. Santamaría A, Santamaría D, Díaz-Muñoz M, EspinozaGonzález V, Ríos C. Effects of $N$ omega-nitro-Larginine and $L$-arginine on quinolinic acid-induced lipid peroxidation. Toxicol Lett 1997; 93: 117-124.

9. Nishikimi M. Oxidation of ascorbic acid with superoxide anion generated by the xanthine-xanthine oxidase system. Biochem Biophys Res 1975; 63: 463-468.

10. Góth $L$. A simple method for determination of serum catalase activity and revision of reference range. Clin Chim Acta 1991; 196: 143-151.

11. Yan F, Wang B, Zhang Y. Polysaccharides from Cordyceps sinensis mycelium ameliorate exhaustive swimming exercise-induced oxidative stress. Pharm Biol 2014; 52: 157-161.

12. Rotruck JT, Pope AL, Ganther HE, Swanson AB, Hafeman DG, Hoekstra WG. Selenium: biochemical role as a component of glutathione peroxidase. Biochem Sci 1973; 179: 588-590.

13. Kinnunen S, Atalay $M$, Hyyppä S, Lehmuskero A, Hänninen $O$, Oksala $N$ Effects of prolonged exercise

Trop J Pharm Res, November 2014; 13(11):1850 
on oxidative stress and antioxidant defense in endurance horse. J Sports Sci Med 2005; 4: 415-421.

14. Fontani $G$, Corradeschi F, Felici A, Alfatti $F$, Bugarini $R$, Fiaschi Al, Cerretani D, Montorfano G, Rizzo AM, Berra B. Blood profiles, body fat and mood state in healthy subjects on different diets supplemented with Omega-3 polyunsaturated fatty acids. Eur J Clin Invest 2005; 35: 499-507.

15. Mergener M, Martins MR, Antunes MV, da Silva CC, Lazzaretti C, Fontanive TO, Suyenaga ES, Ardenghi $P G$, Maluf SW, Gamaro GD. Oxidative stress and DNA damage in older adults that do exercises regularly. Clin Biochem 2009; 42: 1648-1653.

16. Chen Z, Li S, Wang X, Zhang CL. Protective effects of Radix pseudostellariae polysaccharides against exercise-induced oxidative stress in male rats. Exp Ther Med 2013; 5: 1089-1092.
17. Aydin C, Ince E, Koparan S, Cangul IT, Naziroglu M, Ak $F$. Protective effects of long term dietary restriction on swimming exercise-induced oxidative stress in the liver, heart and kidney of rat. Cell Biochem Funct 2007; 25: 129-137.

18. Morillas-Ruiz JM, Villegas García JA, López FJ, VidalGuevara ML, Zafrilla P. Effects of polyphenolic antioxidants on exercise-induced oxidative stress. Clin Nutr 2006; 25: 444-453.

19. Yu F, Lu S, Yu F, Feng S, McGuire PM, Li R, Wang R. Protective effects of polysaccharide from Euphorbia kansui (Euphorbiaceae) on the swimming exerciseinduced oxidative stress in mice. Can J Physiol Pharmacol 2006; 84: 1071-1079.

20. Rahimi R. Creatine supplementation decreases oxidative DNA damage and lipid peroxidation induced by a single bout of resistance exercise. J Strength Cond Res 2011; 25: 3448-3455. 